\title{
An Investigation Into the Advisability of Translating Names of Tibetan Medicine Into Other Languages
}

\author{
Gawai Dorje \\ Translation by Tsering D. Gonkatsang
}

\begin{abstract}
This research article primarily focuses on the author's personal views on the history of translating names of Tibetan medicine into Chinese; the merits of translating (such terms) into other languages like Chinese; issues of improper translation in certain cases; considerations on the advisability of translating names of Tibetan medicine into Chinese and other languages; and the ways and means to resolve this issue.
\end{abstract}

\section{Keywords}

Tibetan medicine; names of medicines; translation

\section{Editors' Introduction}

Dr Gawai Dorje (Dga ba'i Rdo rje) is among the most highly regarded current authorities on Tibetan materia medica identification within the PRC. His publication 'Khrungs dpe dri med shel gyi me long is a mainstay for many doctors of Tibetan medicine and has proved insightful for understanding issues of materia medica classification in contemporary Sowa Rigpa. His current affiliation is through the Tibetan Medical College in Lhasa. He previously practiced medicine as a physician at the Chamdo Prefectural Tibetan Hospital.

Dr Dorje draws our attention in this article to issues of translation. The most pressing issues from his perspective are, not surprisingly, those related to translation of Tibetan terms into Chinese. As anyone who has worked in the PRC is well aware, the dominance of the national language (Mandarin) in publishing and teaching, especially in the sciences, is rather significant. Yet Dr Dorje is not reactionary in his concerns, nor is he linguicentric. In fact, he argues that translation of important Tibetan medical works into Chinese 
is at least in part necessary for the continuation of Sowa Rigpa. But such translations need to be done very carefully, as he explains.

Within any system of knowledge, particularly one as widespread as Sowa Rigpa, there are bound to be variations. This is indeed the case with the naming and identification of materia medica. Partly this is due to distribution of medicinal materials: one species of plant may grow in eastern Tibetan but not in western Tibet, but the two different plants may share the same name in Tibetan. Conversely, two populations of the same species may have two different Tibetan names. A pertinent example in this volume is the plant $r u$ $r t a$; in eastern Tibet (Amdo and Kham) this refers to the species Vladimiria souliei while in western Tibet and parts of Nepal ru rta is identified as Saussurea lappa or $S$. costus. The distinction can be elaborated on in Tibetan with the modification of 'white' or 'black', respectively, for the two kinds of ru rta. Even here the issue of translation is pertinent as we 'translate' between Tibetan and botanical Latin. While most scientists are convinced of the objective reality of species, the classification of the natural world is simultaneously without a doubt a human construct as well-otherwise how could we explain the re-classification and re-ordering of natural kinds in western science (witness the discussion about Cordyceps and Ophiocordyceps in Winkler, this volume)? As human constructions, systems of natural-kind classification undoubtedly reflect the priorities, histories, and propensities of those who have created them.

The issue then becomes even more complex when we factor Chinese language into the translation equation. As Gawai Dorje discusses, many of the Chinese terms used for translation of Tibetan medicine in general (and sometimes specifically for materia medica) come from the Chinese medical tradition. This can present significant problems in terms of conflation or confusion about medical theory, but also in terms of natural-kind identification. As Dr Dorje argues, in the end this can have disastrous consequences for Sowa Rigpa, since if wrongly identified materials that are ineffective are used, this could seriously jeopardize Sowa Rigpa's reputation and overall standing as a respectable and effective system of healing. Dr Dorje's solution is an appeal to a system of romanisation (or Latinisation) that can more effectively transpose Tibetan names into terminology with more widespread currency.

Beyond issues of translation, a noteworthy theme in this article is that of the market. Gawai Dorje displays optimism in his discussion of how Tibetan medicine can benefit from the new market economy. This is telling in terms of what it says about the potential importance of Tibetan medicine in China's new economy - and how Tibetan doctors of Dr Dorje's stature may see Tibetan medicine positioned in this economy-but also about how the market has become a trope for success, development, and progress. 
Finally, Dr Dorje appeals to legal structures in the support of Sowa Rigpa, particularly in the area of standardisation of translations. His argument is one that aims to reinforce institutional structures, many of which he recognises are dominated by Chinese language standards. Yet his call is accompanied by continued education of Tibetan doctors in epistemologies that are centred outside the traditional circuits of knowledge and practice in Sowa Rigpa: specifically, Latin, Chinese, mineralogy and biology. In so doing, Dr Dorje is calling for an almost cosmopolitanisation of Sowa Rigpa.

In the course of editing this essay (and other parts of this entire volume), the very issues of translation that Gawai Dorje discusses were particularly acute, as we note in our introductory essay. Many of the glosses for particular materia medica that were originally identified in the translation of this document needed to be re-visited; it is extremely challenging to make sense of the sometimes overload of terms given in multiple languages for medicinals. We have opted to rely for the most part on identifications provided in Gawai Dorje's own work, 'Khrungs dpe dri med shel gyi me long, since this seemed to provide at least the most consistency, with both works being authored by the same person. However, unavoidable errors have undoubtedly surfaced in the course of this work, for which we take full responsibility.

\section{Introduction}

The following are views based on a limited research on the subject of the beginnings of translating the names of Tibetan medicine into Chinese, its merits, issues, whether appropriate or not, and the ways and means to resolve the issues.

\section{Names of Tibetan medicine and their translation into Chinese}

The Tibetan medical system constitutes the essence of the innovations and sustained practice and experience gained by our ancestors over thousands of years, in the struggle against various kinds of illnesses. With that as the foundation, the tradition has developed further into a complete medical system with its own practice and pharmacology, through the inculcation and supplementation of essential knowledge and practices from other countries such as India and China.

Likewise, with respect to pharmacology, besides the use of medicinal resources (herbs and minerals) that are found in Tibet, the importation and 
use of other potent medicinal resources that grow or are found in other countries like India and China has helped develop and enhance the science of pharmacology and the potency to cure illnesses, and, through sustained practice, evolved into the standard pharmacology that we currently use.

Hence, the terms used for those medicines, too, came to be identified using names based on their respective geographical origins and the local national language. For example, a ru ra [myrobalan, Terminalia chebula], tsan dan [sandalwood, Santalum album or Pterocarpus santalinus], gur kum [saffron, Crocus sativus], dza ti [nutmeg, Myristica fragrans], cu gang [bamboo residue], ba sha ka [malabar nut, Adhatoda vasica or Justicia adhatoda; sometimes Veronica ciliata], ma na ho [agate], ha shig [talc] etc. are exclusively either Indic or Chinese terms. Despite slight corruption of words, use of such (foreign) terms with the associated objects over a long period has rendered them almost like native words. However, such terms carry no inherent meaning or verbal definition in Tibetan language.

Medicinal resources that grow (or are found) in Tibet begot local Tibetan names such as sgron shing [pine, Pinus spp., 'tree of light'], stong ri zil pa [Corydalis spp., 'medicinal herb with dew drops'], bya rgod spos [Delphinium spp., 'vulture plant'], tsher sngon [Meconopsis horridula, 'blue thorny [plant]'], spang rgyan [Gentiana spp., 'an ornament of the meadow'], gla rtsi [musk, 'secretion of the musk deer'], brag zhun [bitumen which is the essence of earth, fossil and pitch effusion of which there are five varieties derived from gold, silver, copper, iron and lead, literally 'melted rock'] etc. These names are given on the basis of etymological justification, legend, and origin or source of the medicinal ingredients. As such they inherently convey meaning and etymological justification and therefore reflect the inherent properties and characteristics of the materia medica. There are also Tibetan terms like dar ya kan [Lepidium spp.], da trig [Rhus spp. or Schisandra chinesis], ${ }^{1}$ dur byid [Euphorbia spp. or perhaps castor-oil plant Ricinus communis], ${ }^{2}$ sho mang [Rumex nepalensis], sne'u [goosefoot, Chenopodium album], ${ }^{3}$ and gro ma [Potentilla anserina] etc. that have origins in Zhang Zhung language and have been arbitrarily coined by ancient Tibetans; these terms seemingly defy

\footnotetext{
1 Editors' note: while we have not been able to confirm this with the author, a possible semantic connection may be that the Rhus genus includes several species that are poisonous, to the skin especially_-poison ivy, oak, etc.-and da trig is also a Bön term for devil. We suspect that there may in fact be important semantic information embedded within this term about the 'perils' of this plant, especially if not properly handled.

2 Editors' note: Ricinus communis has important purgative properties; dur can mean 'to hurry, hasten' so perhaps this semantically relates to purging.

3 Editors' note: sne'u probably means something like blue/green grass.
} 
etymological explanation or definition but are nevertheless native Tibetan terms that have survived to this day. ${ }^{4}$

Nevertheless, commensurate with the changes through the centuries and societal advancement, a wide range of new corpus of knowledge from both within and outside of the country, Tibetan medicine, too, has not escaped their unavoidable influence. For example, since the early part of the twentieth century, Tibetan medicinal terms came to be translated into Chinese, and gradually many new books carrying Chinese terminology as well as Latin (common international) terms appeared, some examples of which are listed here:

- 'Khrungs dpe mdzes mtshar mig rgyan (Elegant and Amazing Manual of the Identification and Classification of Medicinal Resources: A Feast for the Eyes)

- Mdo dbus mtho sgang sman ris gsal ba'i me long (Mirror Clarifying the (Illustrated) Medicines of the Central and Lower Tibetan Plateau)

- Bod ljongs rgyun spyod krung dbyi'i sman rigs (Chinese Medicines Commonly used in Tibetan Areas)

- Bde chen bod sman (Tibetan Medicine of Dechen)

- Bods sman gyi rnam bshad (A Commentary on Tibetan Medicine)

- Bdus rtsi sman gyi 'khrungs dpe legs bshad nor bu'i phreng mdzes (A Precious Garland of Elegant Exposition/Manual of the Identification and Classification of Elixir-like Medicines)

- Krung ha'a sngo 'bum bods man bam po (Tibetan Volume of a Hundred Thousand Herbs of China)

- 'Khrungs dpe'i dri med shel gyi me long (Stainless Crystal Mirror of the Identification and Classification of Medicines) — my own humble book

Additionally, the Rgyud bzhi (Four Tantras on Tibetan Medicine) and Shel gong phreng (Garland of Crystal Rosary) and other such Tibetan medical texts have been translated into Chinese and it goes without saying that all the medical terms used are Chinese. In particular, since the 1980s, along with the opening up of the market economy, the state has strengthened its exercise of control over medical treatment and pharmacology which has made it ever more necessary to translate Tibetan medical terms into Chinese so that books like Rgyal khab kyi sman gzhung chen mo (The Great Medical Texts of the State)

\footnotetext{
${ }^{4}$ Editors' note: while it has been difficult to substantiate this, we believe the author means to imply that the terms that come from Zhang Zhung language may also convey meaning as well (as noted in some of our inserted comments), although the meaning is perhaps somewhat more difficult to discern or has been forgotten in conventional modern usage.
} 
and 'Phrod bsten pu'us spel ba'i bods man gyi tshad gzhi (Standards for Tibetan Medicine established by the Health Ministry) and so on that inherently carry authority and status are entirely published in Chinese language. The terminology used on the labels of medicines in the market, the clarification and diction, are all Chinese; this has accelerated the process of changing Tibetan medical terminology into Chinese which has greatly benefitted the market economy. Besides, this has facilitated the phenomenon of a new generation of Chinese nationals who have emerged and continue to emerge as experts in Tibetan medicine.

\section{Merits of translating medical terms into other languages}

In order to properly identify the nature and composition of the materia med$i c a$, one must have a thorough knowledge and understanding of the source of the medicine and the native terminology used for that medicine. Borrowing and relying on a foreign language and terminology will inevitably suffer corruption over time and will not be able to accurately reproduce the original terms and their sounds. So, if the term is a Chinese word, a proper knowledge of Chinese language would preclude corruption of the term and its pronunciation. With the exception of medicines that originate in Tibet, others that originate in India or China and are used in Tibetan medicine should all be procured through a proper and accurate knowledge of the local medical terminology, including pronunciation. Otherwise, without accurate translation into Sinic or Indic languages, it would be impossible to obtain standard medicinal materials; and even if one were to obtain them, the costs are bound to be exorbitant. On the other hand, if the translation of the materia medica can be done accurately according to a high standard, we can procure the needed materia medica conveniently since the market of medicinal materials in both China and India is as buoyant as the general market economy. This will widen and enrich the sources of Tibetan materia medica which in turn would raise the standard and quality of Tibetan medicinal production and conspicuously help raise the [perceived] curative effectiveness/potency of traditional Tibetan medicine.

As the State laws and their enforcement become more established and systematic by the day, be it western medical system or the Chinese medical system or the medical systems of the minority nationalities, the process of reform and sustenance based within the framework of the law is getting more established. Therefore, the translation of Tibetan medical system terminology and pharmacopeia into standard Chinese language would only facilitate and 
help obtain greater protection by the law, supervision by the law and enhance the legality of Sowa Rigpa practice.

If we wish to promote the Tibetan medical system and pharmacology outside the TAR or outside the [Chinese] state to other countries of the world, only through translation into Chinese, English and into the languages of the various countries would we be able to share the shining and glorious medical tradition of our nationality throughout the world. At the same time, this will help us learn and imbibe new things that represent the essence and potent qualities of the medical systems of other countries, and thus, make our medical and pharmacological system more enriched and complete.

There are many further justifications and benefits. As such, the efforts to translate the corpus of knowledge and terminology of Tibetan medicine and pharmacology into other languages should be further strengthened. Those engaged in Tibetan medicine should endeavour to study other languages and medical traditions, and in particular, focus on the modern fields of knowledge such as mineralogy, botany, and biology so that they can contribute to broadening the horizon of Tibetan medicine and making it compatible with the needs and pace of the modern times as well as societal development in the future.

\section{Some issues concerning the translation of names of medicines into Chinese}

The pace of change with the times and the rate of societal progress is not only very fast but also, and in particular, the competitiveness of the market economy is fierce. The pace of change and adaptation of Tibetan medical practice and pharmacology to the market economy is gathering momentum, and the pace of translating Tibetan medical knowledge and medical terms into Chinese language is also catching up accordingly. However, in the process of such translation work, cases of inaccuracies in translation are becoming apparent for which there are many causal factors.

For one, when one's level of proficiency in language and standard of education is not high to begin with, it would be extremely difficult to get a proper understanding of the theory and practice of the Tibetan medical tradition. Translating such a tradition and the medical terminology becomes even more challenging. And on top of that, since there is no escaping the reliance on loan words from Chinese and foreign medical traditions, an accurate translation of the facts at hand become supremely difficult. Hence, these days there are people who have a respectable degree of proficiency and 
command over the Chinese language but without any basic knowledge and understanding of Tibetan medicine and pharmacology; those who may have attained mastery over both Tibetan and Chinese languages but are lacking in any kind of study of the technical terms of the medicinal raw materials and do not have experience studying modern biology and botany; and such translators whose partial expertise or translators who know nothing about the subject rampantly copy from right and left, resulting in the errors in translations and inaccuracies that are evident [in their translated texts].

Thus, there are instances of translating by coining new words, and providing a glossary to explain the newly coined words associated with the particular medicinal raw material, such as: gro ma [Potentilla anserina L.] as renshen guo 人参果 [ginseng fruit], go snyod (common caraway cumin seed, Carum carvi L.) as zanghuixiang 藏茴香 [Tibetan fennel], gzi (Onyx/Divine agate stone) as jiuyanzhu 九眼珠 ['nine eye pearl'], dbang ril [empowered pill] as fuzhongbo 腹中宝 ['belly full treasure'] etc. Through the process of familiarisation and identification the new terms may get established where there do not exist materials that share the same names. As such, this process may not result in any seriously negative consequences.

Likewise in some 'khrungs dpe [pharmacopoeia] there are many errors in Chinese translations. For example, for mu men [Lapis lazuli, or Liguritum] where the proper Chinese word given is qingjinshi 青金石 [blue/green metal stone], the translator has written qingjingshi 青晶石 [blue/green brilliant stone]; for stab seng [Fraxinus spp.], the Chinese word is qinpi 秦皮 but the translator has written taipi 泰皮; for skyer pa [Berberis spp.] the Chinese word is xiaobo 小檗 but the translator has written xiaonie 小莧; for ma ru rtse [Butea monosperma] the Chinese word is zikuang 紫5 but the translator has written zimao 紫钟, and so on according to the whim and fancy of publishers and typists and the lack of rigour in editing by editors.

Such lapses may not be too damaging to those reading in Tibetan but for those reading in Chinese language, especially those researching or practising Tibetan medicine, it would result in the near impossibility to find medicinal resources with such neologisms. It would not, however, be able to cause any serious consequences on the identification of Tibetan medicinal resources.

The key issue is the problem resulting from the practice of copying or using Chinese medical terminology wantonly either from Chinese medical texts or from glossaries of Chinese medical terminology, without analysing the actual (Tibetan) medicinal resources. Consequently the terms do not

\footnotetext{
5 We have been unable to locate the second character of this compound (pinyin: kuang) in the Microsoft input version of Chinese language for Word documents.
} 
match the medicinal resource. For example, some have used words based on the meaning of Chinese words: jixiangcao 吉祥草 [auspicious grass] for $k u$ sha [Thysanolaena maxima], xianren zhang 仙人掌 [immortal's palm] or foshou 佛手 [Buddha's hand] for dbang lag [Gymnadenia orchidis, literally 'powerful hand'], fangjieshi 方解石 [calcite, literally 'four division stone'] for gru $b z h i$ [Limonite, literally 'four corner'] and so on.

Others have used words based on slight similarity in the sounds of the words (in Tibetan and Chinese), for example: $y u s h i$ 玉石 for $g . y u$ [turquoise], danggui 当归 for tang kun [Sinolimprichtia spp.], huanglian 黄连 for hong len [Lagotis spp.] and so on. Yet others have used words based on the slight resemblance in shape and colour without checking the source or the medicinal resource itself. For example, wulingzhi 五灵脂 [faeces of the flying squirrel] for brag zhun [bitumen], yapian 芽片 ['bud slice'] or 鸦片 [opium] for rgya men [Papaver spp.], xiangfuzi 香附子 [fragrant monkshood] for gla sgang [Polygonum sphaerostachyum], chuanshanjia 穿山甲 ['penetrate mountain shell'] for $n a g i$ [scale of the pangolin, Manis pentadactyla] and so on.

And some have, without any justification, assuming that each medicine needs a specific Chinese term, used any term, Chinese or Latin. For example, wuweizi 五味子 ['five tastes'] for da trig [Rhus spp.or Schisandra chinesis], shechuangzi 蛇床子 ['snake bed'] for la la phud [Foeniculum vulgare], mubiezi 木鳖子 ['wooden soft-shelled turtle'] for gser gyi phud bu [Luffa cylindrica, seeds of the luffa plant], hailanbaoshi 海蓝宝石 ['ocean sapphire'] for khyung skyug [Jasper], luganshi 炉甘石 [calamine] for gangs thigs [gypsum] and so on.

The above listed are just a few of the most conspicuous examples of (inappropriate) translations; furthermore, there are many translations of the names of medicinal resources that are bad. Such poor translations as the above sampling represents will have very serious consequences because the Chinese terms used have meanings that refer to medicinal resources or other things but not related to the Tibetan medicinal resources being referred to. Using them without investigation, then, would render it impossible to achieve the medicinal benefits as described in the (Tibetan) medical texts, and the potency of most of the medicinal concoctions would go wrong and fail to cure the illness as intended. And over time, it would become hard to correctly identify Tibetan medicinal resources; as such, how could we develop the Tibetan medical tradition?

Furthermore, there are even more serious cases. For example, consider the ongoing objection and dispute to Geshey Chodak and others for translating the Tibetan word brag zhun [bitumen] from Chinese medicine as wulingzhi 五灵脂 [faeces of the flying squirrel] on the ground that it contradicts the 
meaning as implied in the standard Tibetan medical texts. New translations such as hongershutu [red eared mouse rabbit] (Ochotona erythrotis Buchner or perhaps wei shutu ke honger shutu de fen, literally 'the excrement of the redeared mouse-rabbit of the mouse-rabbit family') suggests that brag zhun is the excrement of the red eared, tailless rodent [Chinese Red Pika]. [This mistranslation] defines the rodent, its geographical environment, and the properties of its excrement in a precise manner and additionally, attributes to it the flavour and curative efficacy of brag zhun by citing [Chinese] sources etc. Moreover, by citing brag zhun as a category of medicine that is obtained from living organisms, it is not merely a case of using a Chinese term in (inappropriate) translation but also fundamentally changing the very nature of the medicine. Hence, does not this constitute a disregard and contempt of the pronouncements of Jetsun Yuthok [Yonten Gonpo] and other medical scholars like Byang Zur (byang pa rnam rgyal grags bzang and zur mkhar mnyam nyid rdo rje) and other great forefathers, that bitumen is the essence of a rock that is obtained from the craggy mountains which is one of the six possible sources of gold and others?

I consider the above anomalies, not as a reflection of the slight differences in the viewpoints as held by the two [Sowa Rigpa] traditions of Byang (and) $\mathrm{Zur}^{6}$ as well as amongst medical practitioners in the three provinces of Tibet but rather as a fundamental shortcoming resulting from the translation into Chinese language and use of terms that mean and imply things that have never been used as ingredients or resources of (traditional) Tibetan medicine.

\section{Varying views and opinions on the issue of translating Tibetan medicinal (pharmacology) terms into Chinese language (Mandarin)}

Basically, there are varying viewpoints amongst scholars on the issue of translating Tibetan medicinal (medical) terms into Chinese (Mandarin). Some consider it advisable to make such translations whereas others object to these endeavours. And there are those who consider it advisable to phonologically transcribe the Tibetan medicinal terms directly and accurately into Chinese language (Mandarin). All these viewpoints and opinions do have their justifications and are intended to benefit the interests of the Tibetan medical tradition. However, as a result of the silence and non-involvement of those who

${ }^{6}$ The Northern (byang lugs) and Southern (zur lugs) schools or traditions of Tibetan medicine flourished in the fifteen and sixteenth centuries in Tibet. For more information on these two streams of Tibetan medical history, see Hofer 2007 and Gerke 1999. 
are experts in traditional Tibetan medical practice and pharmacology, in terms of the issue at hand, this has only afforded greater opportunities for the brazen few to wantonly translate (Tibetan medical terms) as they please. And, (also) the tendency of such (Tibetan medical) scholars to sign such books without checking the consequences of such (inappropriate) translations is a regrettable matter. If one were to carefully analyze the aforementioned three kinds of viewpoints/opinions, it would not do merely to consider their merits from one angle only but rather from different angles because [of three reasons].

First, even though there are many merits in translating Tibetan medical terms into Chinese, as a consequence of indiscriminate and careless attitudes during the course of translation work, there can be a lack of correspondence between the medical terms and the supposed medical resources. This in turn, is going to be a source and cause of the perpetuation of mistakes in the identification of Tibetan medicine in the future. Additionally, there is a risk of rendering the unique teachings and practice of Tibetan medical tradition and pharmacology as useless as the village garbage that anybody could pick up. Therefore, it is of utmost importance to pay attention to the process of translation work and consider whether or not certain forms of translation are worth it or not.

Second, in case medical terms are not translated into Chinese, and if we cannot facilitate a proper understanding of the correct Chinese names for the Tibetan medicinal resources, then there will be (negative) consequences with respect to the preservation and continuation of the (identification) of (Tibetan) medicinal herbs and minerals, research, innovation and development. Furthermore, this is going to adversely affect the legal management (of Tibetan medicine) according to state laws, necessitate circuitous bureaucratic procedures and render it hard to obtain legal protection. And the chances of Tibetan medicine for getting beyond the borders of the TAR and the state would be a well nigh impossible.

Third, if all Tibetan terms for Tibetan materia medica were to be phonetically transcribed into Chinese, then such terms would create problems for many other nationals who have their own native terms for those materials, and who do not necessarily read Chinese. [In this instance,] the Tibetan terms written phonetically may not be comprehensible to them nor would it help them to identify and obtain the correct medicinal resources. Instead, if necessary, phonetically writing the Tibetan names for medicinal compounds [in Roman / Latin script, based on original Tibetan spellings] would be slightly more appropriate because such compounds would be unique to the Tibetan medical tradition. And with the passage of time and increased exposure people could become familiarised with such terms. However, that is not 
an easy thing to achieve. Since there is considerable variation in the dialect and accent according to regional differences in reading [and sometimes writing] the same Tibetan words, we recognize that phoneticising accurately the Tibetan names of medicinal resources, particularly into Chinese language, will be highly challenging.

\section{How should we resolve such issues in the future?}

Broadly speaking, it is a sign of the backwardness of a people to have an attitude of dislike towards the promotion of a language that one does not know oneself. The thinking that translating Tibetan medicinal terms into Chinese is a very complicated issue and should be discarded is not going to be realized. We are already in the twenty-first century, and the advance of time is, like the movements of the earth, unstoppable. Therefore, instead of trying to stop it, it would be more beneficial to march ahead in tune with the times. The issues and erroneous views highlighted above are the result of ignorance rather than any intentional attitude to mistranslate Tibetan medicinal terms (into Chinese). Such shortcoming are likely to have occurred as result of senior (Tibetan) medical scholars' failure to raise objections or failing to notice such lapses rather than any (irresponsible) attitude on their part, thinking, 'My life is over. Let them do what they like.'

Hence, basically, by strengthening the foundation, efforts should be redoubled to translate Tibetan medicinal terms into Chinese language more accurately, and in particular, the international mode of Latin script should be used (for phonetic transcriptions). And it goes without saying that there is a need to train and nurture an educated and specialist (Tibetan) manpower who are well versed in the areas of identifying Tibetan medicinal resources, Chinese language, modern mineralogy, botany, biology and so on. In the institutions of higher education in the Tibetan medical system, there should be provision in the curriculum for the study of modern biology and Latin language. Whilst undertaking projects to translate Tibetan medical terms into Chinese or where labelling and descriptions of Tibetan medicines are required, there should be (legal) requirements that such translations obtain the (official) approval of standard bodies responsible for the management and supervision of medicinal resources as well as the clearance of specialists in the relevant subject fields. Furthermore, any other beneficial ways and means to facilitate and support the task of translating the names of Tibetan medicine should be explored.

This short essay is neither a rigorous intellectual investigation nor an exercise in poetics but rather a (humble) submission to learned scholars by some- 
one who is seriously concerned about the future of the work of identification of Tibetan materia medica after coming across various erroneous views and facts while undertaking a comparative study of reference manuals and various other texts. I have been impelled by the realization that if nothing was done and the errors were perpetuated, some of the salient issues that have been highlighted here would continue. Therefore I request the scholars with fame and authority and leaders not to let this matter go unattended but instead, analyse, clarify, criticize and suggest alternatives that may be appropriate. And (finally) I urge the young and intelligent people to keep these in mind as counsel from an elder of the past.

\section{References $^{7}$}

Tibetan sources

De'u dmar Bstan 'dzin Phun tshogs. Dri med shel 'phreng.

Krang Dbyin sun et al. (eds). Bod rgya tshig mdzod chen mo.

Cha har Dge bshes. 'Khrungs dpe mdzes mtshar mig rgyan.

Karma Chos 'phel. Bdud rtsi sman gyi 'khrungs dpe legs bshad nor bu'i phreng mdzes.

Dga' ba'i Rdo rje. 1995.'Khrungs dpe dri med shel gyi me long. Beijing: Mi rigs dpe skrun khang.

\section{Chinese sources}

Krung hwa Sngo 'bum Rtso sgrid khang (eds). Krung hwa sngo 'bum bod sman bam po.

杨竟生, 初称江措 Yang Jingsheng and Chuchen Jiangcuo (Tsultrim Gyatso). 1987. 迪庆藏 药, 上册 and 下册 Diqing Zangyao, shangce, xiace. 昆明: 云南民族出版社 Kunming: Yunnan minzu chubanshe.

De'u dmar Bastan 'dzin Phun tshogs. Dri med shel 'phreng. (Chinese translation by Ma'o Cis tsu'u et al.).

Rgyud bzhi (Chinese translation by Lis Yung nyan).

English sources

Gerke, B. 1999, 'On the history of the two Tibetan medical schools Janglug and Surlug', AyurVijnana 6, Spring 1999 issue.

Hofer, T. 2007, 'Preliminary investigations into new oral and textual sources on Byang lugsthe "Northern School" of Tibetan medicine', in M. Schrempf (ed.), Soundings in Tibetan Medicine; Anthropological and Historical Perspectives, Leiden: Brill, 373-410.

${ }^{7}$ Editors' note: at the time of publication, we were not able to obtain full citations for several of the references cited here. 